\title{
Role of Big Data and Analytics to Enhance the Higher Education in India
}

\author{
Sanjay Kumar Sinha \\ Research Scholar, CSE \\ Jaipur National University \\ Jaipur, India
}

\begin{abstract}
This Paper explores the Role of Big Data and Analytics in Higher Education Sector in India. It also shows the current challenges to enhance the Higher Education, Student retention, Student learning Progress. This Research paper Concludes Big Data utilization in Higher Education sector to enhance the decision support to higher management. The aim of this paper is to explore the current landscape of big data and its potential for use in the Higher Education sector in India. We will be also presenting a framework to capturing data, analyzing data and concluding data to benefit for decision making .In this Paper there exists a difference between traditional data and big data. This Paper reviews the state of Big data Analytics, Consider possible application in Indian higher Education and finally yet identify challenges about Big Data Analytics.
\end{abstract}

\section{Keywords}

Big Data, Higher Education, Big Data Analytics, Traditional Data

\section{INTRODUCTION}

Big Data in higher education covers database systems that store large quantities of longitudinal data on students' right down to very specific transactions and activities on learning and teaching. When students interact with learning technologies, they leave behind data trails that can reveal their sentiments, social connections, intentions and goals. Researchers can use such data to examine patterns of student performance over time - from one semester to another or from 1 year to another. This Paper addresses the retention rate issue, provides a history of big data, examines the analytic methodologies by understanding the role of big data and data analytics in higher education, it is hoped that more institutions will adopt technologies in order to better support their students.

\section{LITERATURE REVIEW}

Many scholars have different views about Big data. Definition of Big Data Yet not clear."Big Data means those big scale data which goes beyond the traditional rule and which is hard to be captured by common software tools" [3].We call it "big" is not only because of its huge capacity but also because of its greater significance in discovering new knowledge and creating new value through exchange, integration and analysis of massive data so that we could get "big knowledge", "big technology", "big profit" and "big development" [4]. American Internet data center defined big data as a new Kind of technology architecture which obtains value from large quantities of data by high-speed capture, detection and analysis. Wikipedia definition of big data is straightforward. Big Data usually includes data sets with sizes beyond the ability of commonly used software tools to capture, curate, manage, and process the data within a tolerable elapsed time
[5]. Indian Higher Education sector has grown dramatically in recent years. Analytics, data science and big data industry in India is currently estimated to be Rs 17,615 crore annually (FY18) in revenues (Dataquest estimates). A sizeable 22\% can be attributed to big data. Analytics, data science and big data industry in India is expected to grow seven times in the next seven years. It is estimated to become a Rs 1,30,000 crore industry in India by 2025(Dataquest estimates).

\section{BIG DATA ANALYTICS}

Big data and analytics in higher education can be transformati -ve, altering the existing process of administration, teaching and learning and contribute to the policy outcomes by helping to the address existing challenges faced by the educational institutions [1]. Big Data Analytics in higher education can be divided into two categories. Learning analytics focus on capturing student behavior and correlating it to achieving learning objectives, while academic analytics tries to design predictive analytics for student attainment. There are many areas in which universities could benefit from making use of Big data analytics. These include increasing retention, providing better feedback to student, capturing attendance data and enhancing teaching and learning and contain costs .If data can be used so effectively to enhance student learning, reduce time to graduation, it begs the question whether it can also be used to improve the quality of teaching [2]. Nowadays the higher education institutions more and more technologies oriented. The two important tools mostly used in higher Educational institutions like Virtual Class Room and MOOCs (Massive open Online Courses).These Massive Open online Courses generating huge amounts of data which are relevant for Big Data and Analytics. The Virtual Class Room is also important tool where an instructor can share learning materials through distance learning programs. Through Big data Analytics has potential to positive impact of all areas of institution such as student enrolment and retention, information management, operational cost management. Higher institutions can perform analyses of student and learning data to make decisions in future courses for the needs of potential existing candidates. Many Universities and colleges have demonstrated through Big data analytics to significant develop an institution in such areas as resource allocation, student access and finance. Big Data analytics can help organizations to better understand the information contained within the data and will also help identify the data that is most important to the business and future business decisions. Analysts working with Big Data typically want the knowledge that comes from analyzing the data

\subsection{Big Data Analytics in Higher Education}

Through Big data Analytics we will able to solve many challenges facing in higher education in India. In most examples academic performance is used to measure student 
performance including study, social habits, sleep, passion for the study and faculties effectiveness determine how student performs. In more recent times using big data in accessing individual students creates a more personalized learning environment for the students as it provides the teachers with information on the student's interest, prior knowledge of the course being taught and the student's academic ability. This allows the teacher to know which student is not being carried along and adopt suitable teaching methods to accommodate such students. Big data can support the classic educational system by improving teacher- student effectiveness [4] There are advantages of implementing Big Data Technology in Education is Effective System Administration, Matching students to corresponding programs, customized learning procedures, restructuring of learning curriculum, capable candidates to suitable employments. According to T. Erl, W. Khattak, P. Buhler (2016), data analytics includes the management of complete data life cycle, from collecting data, cleansing, organizing, storing, analyzing, to data governing. In the context of Big Data, data analytics is focused on managing large volumes of data using highly scalable distributed technologies.

\subsection{Analysis of Big data and traditional Data in Higher Education}

We can analyze of Big Data and traditional Data used in Higher Education through this process. In Big data and traditional Data in Higher Education a) Volume- HEI should use data in the form of structure data, unstructured data, and traditional data through networks but recently used data in higher Education from Registration data, Assessment data, Graduate data, and complaint data. b) Variety-HEI should use data through DBMS, data from Web, data from social network, data from relational tables but recently used data in higher education from different process of teaching method, virtual classes, increasingly unstructured formats. c) VelocityHEI should use data through speed of access data is being generated fast, through online data analytics methods but recently used data in higher education collected data analyze quickly like Assessment details, student admission results, expected graduate list. d) Veracity- HEI should use data through implementing validation data analytics like quality data, credible results, critical decision making but recently used data in higher education of skilled graduates, high quality education like preparing students results, evaluation assessment quality, and identification learning objectives.

\section{APPLICATIONS OF BIG DATA AND ANALYTICS IN HIGHER EDUCATION IN INDIA}

Big data and Analytics can be applied various types to enhance the higher education in India like administration applications, admission and recruitment processing, student performance monitoring, financial planning. Big data experts say Big data analytics would be an integral part of the nations plan. Big Data is a knowledge system that is already changing the objects of knowledge and social theory in many fields while also having the potential to transform management decision-making theory [9]. Big Data incorporates the emergent research field of learning analytics (Long \& Siemen, 2011), which is already a growing area in education. However, research in learning analytics has largely been limited to examining indicators of individual student and class performance. Big Data brings new opportunities and challenges for institutions of higher education. Long and Siemen (2011) indicated that Big Data presents the most dramatic framework in efficiently utilising the vast array of data and ultimately shaping the future of higher education. The application of Big Data in higher education was also echoed by Wagner and Ice (2012), who noted that technological developments have certainly served as catalysts for the move towards the growth of analytics in higher education.In the context of higher education, Big Data connotes the interpretation of a wide range of administrative and operational data gathered processes aimed at assessing institutional performance and progress in order to predict future performance and identify potential issues related to academic programming, research, teaching and learning[10]. In the new era of which every information is very important for teachers, students and staff of any University in India. There are various mode using Big data to get benefit for students ,Teachers and University Administrators.that the word for Table and Figure are spelled out. Figure's captions should be centered beneath the image or picture, and Table captions should be centered above the table body.

\subsection{Developing a new Teaching mode}

In current year Lockdown in India due to Covid 19(Corona Virus)Pandemic, total Universities, Colleges and Schools are closed. The complete Education System has crashed. At this time online study is becoming a major way for learning. On the Internet, Students have access of the Indian Universities as well as World's best courses which are better than the courses that are offered by any single university. Through online teaching method large volumes of data were generated.HEI can apply the method of Big data and Analytics in Higher Education to enhance the system of India.

\subsection{Provide Online platform for Education}

Since last few years, online education changes the education system in India. If education will continue to move online then there is a need to be culture shift where both students and tutors can take more benefits. Through traditional Education system Higher Education has no storage students data, manage Administrative system, Students examination details. If HEI provides online platform for higher education then Indian higher Education system can improve traditional education system through Big data analytics.

\section{CHALLENGES \& OPPORTUNITIES}

As an emerging field within education, a number of scholars have contended that Big Data framework is well positioned to address some of the key challenges currently facing higher education (see, eg, Siemens, 2011). At this early stage much of the work on analytics within higher education is coming from interdisciplinary research, spanning the fields of Educational Technology, Statistics, Mathematics, Computer Science and Information Science. A core element of the current work on analytics in education is centred on data mining. Big Data in higher education also covers database systems that store large quantities of longitudinal data on students' right down to very specific transactions and activities on learning and teaching. When students interact with learning technologies, they leave behind data trails that can reveal their sentiments, social connections, intentions and goals. Researchers can use such data to examine patterns of student performance over time-from one semester to another or from 1 year to another. On a higher level, it could be argued that the added value of Big Data is the ability to identify useful data and turn it into usable information by identifying patterns and deviations from patterns. 


\subsection{IT Infrastructure}

Results of IT analytics are used to develop rigorous data modeling and analysis to reveal the obstacles to student access and usability and to evaluate any attempts at intervention. Hrabowski and Suess (2010) reported that with analytics, IT systems can help by refining the associated business processes to collect critical data that might not have been collected institutionally and by showing how data in separate systems can become very useful when captured and correlated. Academic analytics through IT will be an essential component of the future. It encapsulates all the activities in higher education affecting administration, research, resource allocation and management [11]. Academic analytics provides overall information about what is happening in a specific programme and how to address performance challenges. Academic analytics reflects the role of data analysis at an institutional level, whereas learning analytics centres on the learning process (which includes analysing the relationship between learner, content, institution, and educator) (Long \& Siemen, 2011). Learning analytics is concerned with the measurement, collection, and analysis and reporting of data about learners and their contexts, for purposes of understanding and optimising learning and the environments in which it occurs (Long \& Siemen, 2011).

\subsection{Learning Analytics software}

More broadly, learning analytics software and techniques are commonly used for improving processes and workflows, measuring academic and institutional data and generally improving organizational effectiveness[12]. Although such usage is often referred to as learning analytics, it is more associated with 'academic analytics' [13] Learning analytics is undertaken more at the teaching and learning level of an institution and is largely concerned with improving learner success(Jones, 2012). Associated with learning analytics is the notion of teacher analytics. Xu and Recker (2012) extended learning analytics to include teaching analytics. In their work, they analysed teachers' online behaviours in the context of utilising digital library and online resources. They utilised educational data mining techniques to identify different groups of instructional architectures to determine diverse online behaviours. Big Data and analytics in higher education can be transformative, altering the existing processes of administration, teaching, learning, academic work (Baer\&Campbell, 2011), contributing to policy and practice outcomes and helping address contemporary challenges facing higher education.

\subsection{Using Predictive tools}

Big Data can provide institutions of higher education the predictive tools they need to improve learning outcomes for individual students as well ways ensuring academic programmes are of high-quality standards. By designing programmes that collect data at every step of the students learning processes, universities can address student needs with customised modules, assignments, feedback and learning trees in the curriculum that will promote better and richer learning. One of the ways higher education can utilise Big Data tools is to analyse the performance and skill level of individual students and create a personalised learning experiences that meet their specific learning pathways. When used effectively, Big Data can help institutions enhance learning experience. and improving student performance across the board, reduce dropout rates and increase graduation numbers. Basu (2013) indicated that prescriptive analytics enables decision makers to look into the future of their mission critical processes and see the opportunities (and issues) as well as presents the best course of action to take advantage of that foresight in a timely manner. Furthermore, most of institutional data systems are not interoperable, so aggregating administrative data, classroom and online data can pose additional challenges[14]. Furthermore, data integration challenges are eminent, especially where data come in both structured and unstructured formats and needed to be integrated from disparate sources most of which are stored in systems managed by different departments. Additionally, data cleansing when performing integration of structured and unstructured data is likely to result to loss of data. There are also challenges associated with quality of data collected and reported. Lack of standardized measures and indicators make inter(national) comparison difficult, as the quality of information generated from Big Data is totally dependent on the quality of data collected and the robustness of the measures or indicators used

\section{IMPLEMENTATIONS}

A recent U.S. Department of Education (2012) report suggested that the successful implementation of Big Data in higher institution would depend on collaborative initiatives between various departments in a given institution. For instance, the involvement of IT services departments in planning for data collection and use is deemed critical. This is consistent with views that the value of Big Data will be based on the ability to co-create governing structures and delivery of more progressive and better policies and strategies currently used [15].Wagner and Ice (2012) also pointed out that by increasing collaborative ventures on Big Data initiatives help all groups take ownership of the challenge involving student performance and persistence. Dringus (2012) suggested that the practice of learning analytics should be transparent and flexible to make it accessible to educators (Dringus, 2012; Dyckhoffet al, 2012). However, there is still a divide between those who know how to extract data and what data are available, and those who know what data are required and how it would best be used, all which make collaboration difficult. Furthermore, as Romero and Ventura (2010) note, analytics has traditionally been difficult for non-specialists to generate (and generate in meaningful context), to visualise in compelling ways, or to understand, limiting their observability and decreasing their impact (Macfadyen \& Dawson, 2012). The importance of communicating these ideas is also acknowledged by Macfadyen and Dawson(2012), who pointed out that analytics have a negative or neutral impact on educational planning. They advocate delving into the sociotechnical sphere to ensure analytics are presented to those involved in strategic positions in ways that have the power to motivate organizational adoption and cultural change. Becker (2013) suggested three interactive components to be studied when collecting data for analytics: location, population and timing. Location is defined by where and how students are accessing the learning space, whereas population refers to the characteristics of the group of learners participating in the learning space. Timing can be defined by any unit, from second or minute to semester or year. Big Data utilisation also raises issues around ethics of data collection in regard to quality of data, privacy, security and ownership. It also raises the question of an institutions responsibility for taking action based on the information available (Jones, 2012).

\section{SECURITY AND PRIVACY ISSUES}

Security and privacy issues pose additional challenge to implementation of Big Data in higher education. Currently, techniques such as disaster recovery plans, strong password policy, firewalls, encryption and anti-virus software that 
reduce the risks of losing or manipulating Big Data are still being investigated. Furthermore, risks and security procedures for data protection and privacy are still lacking in many institutions of higher education. For instance, Slade and Prinsloo (2013) pointed out that while most higher education institutions seem to have policies to regulate and govern intellectual property, safeguard data privacy and regulate access to data, these policies might not be adequate to address contemporary challenges associated with Big Data in higher education. Dringus (2012) for example argue that bringing transparency to learning analytics as a practice could be used to help deter any potentially wrongful use of data. As the amount of data available for use is ever-increasing, the benefits will come from good learning management, reliable data warehousing and management, flexible and transparent data mining and extraction, and accurate and responsible reporting[16].The purpose and value of higher education is transforming. Technology is strengthening the capabilities of institutions to face the new challenges. Higher education has access to realms of data which can be used to improve decision making. The use of Big Data and analytics in higher education is relatively new area. As a result, various types of distributions and technologies have been developed. Comparisons according to different system layers such as Data Storage Layer, Data Processing Layer, Data Querying Layer, Data Access Layer, Big data- which is maturing over time, has a high impact in analyzing scenarios and coming up with decision making strategies pertaining to any sector[17]. Consequently the number of applications is also increasing where in the past, they were limited to the confines of company sales departments. B. Education Sector In the education sector, higher-education possesses the most expensive programs linked to government research grants. For instance, medical sciences have the most approved budget to develop candidates into specialist practitioners. The nature of their essential role within society ensures that governments keep investing into contextual research programs. The same goes to differing extents for robotics, aerospace, mechanics and space technologies etc. To effectively utilize the budget in these respects, it is pertinent to understand the capacity of an enrolled candidate. Either the candidate has potential upon which such investment should be made or it will result in wasted money in the case of serious underperformers -thus not allowing a viable return on investment in terms of the benefit accrued to overall society through such expenditure. Thus the importance of understanding the capacity of enrolled students and extrapolating from this their likelihood of succeeding is highlighted here. 978-1-5090-2594-7116/\$31.00 (C)20 16 IEEE 3 this is where Big Data application can play a major role. With the Internet of Things (loT), one can have overall stream of data for the entire varsity, various programs, classes, teachers and students from which various analyses can be performed.

\section{CONCLUSIONS}

Large amounts of data generated everyday in various fields. This paper examined by using big data technology, tools and methods how to enhance the higher education systems in India. This paper aims to improve communication between the students and administration. It is very necessary to shape our Universities for future. This paper improves the productivity of education outcomes using its technology all over the education systems levels, at teaching, learning, retention, administration, and reporting. The value of analytics and Big Data in higher education is in reform activities and improving teaching, learning process. This paper is a review that survey recent technologies developed for Big Data. It aims to help to select and adopt the right combination of different Big Data technologies according to their technological needs and specific applications' requirements. It provides not only a global view of main Big Data technologies but also and Management Layer. It categorizes and discusses main technologies features, advantages, limits and usages. According to this paper is primarily focused on applying Data Sciences within the education sector. General With the mass utilization of different technologies, there is now a stream of data available. This stream is not just garbage, but has key impact in terms of containing valuable patterns that give meaning to different scenarios. This may include identifying patterns of the society, what's being discussed in premises, what people are valuating to, who are potential customers etc. Big data Analytics can help universities to understand current performance and adjust shortfalls and also develop programs to changing digital economy. It is essential to shape the successful university of the future. There is potential for Big data analytics to be used to help institutions to support their students through their educational journey. Thus, all institutions should considerintroducing an appropriate Big data analytics system to improve student support and performance

\section{ACKNOWLEDGEMENTS}

I am very grateful to my guide Dr Harvir Singh, Director, Jaipur National University, Jaipur and my friend Research Scholar BIT,Mesra Mr Sandip Singh Modak to continuous support and motivate to write this paper.

\section{REFERENCES}

[1] Riffai. M.M.M.A., Edgar David, Duncan Peter, Ahmed Hassan Al-Bulushi, 2016 3rd MEC International Conference on Big Data and Smart City The Potential for Big Data to Enhance the Higher Education Sector in Oman.

[2] Mukthar Ayesha, Sultan Meshael, Big Data Analytics for Higher Education in Saudi Arabia, International Journal of Computer Science and Information Security (IJCSIS) Vol. 15, No. 6, June 2017.

[3] TU ZIPEI. Big Data: revolution is coming [M].NANING: Guangxi Normal University Press, 2012, pp57.

[4] Gantz,John and David Reinsel. "Extracting value from chaos". IDC iview1142.2011(2011):1-12

[5] "Big Data". Big Data- Wikipedia. Wikipedia, 28 May 2017.Web. 29 May 2017.

[6] Ekong E.E, Adiat Q.E.,Ejemeyovwi J.O.,Alalade A.M, Harnessing Big Data Technology to Benefit Effective Delivery and Performance Maximization in Pedagogy, IJCIET January 2019.

[7] T. Erl, W. Khattak, P. Buhler, Big Data Fundamentals: Concepts, Drivers \& Techniques, Boston: Prentice Hall, 2016.

[8] Naganathan Venkatesh, Comparative analysis of Big Data, Big Data Analytics: Challenges and Trends, International Research journal of Engineering and Technology, 5 May 2018.

[9] (Boyd \& Crawford, 2012)

[10] (Hrabowski, Suess \& Fritz, 2011a, 2011b; Picciano, 2012) 
[11] Significance of Big Data and Analytics in Higher Education(Tulasi, 2013)

[12] (Dyckhoff, Zielke, Bültmann, Chatti \& Schroeder, 2012; Jones, 2012)

[13] (Goldstein \& Katz, 2005).

[14] Technology Enhanced Analytics in Higher Education(Daniel \& Butson, 2013)
[15] (Schleicher, 2013).

[16] B.Tulasi Assistant Professor Department of Computer Science, Christ University ,Bangalore, India

[17] 2016 IEEE International Conference on Cloud Computing and Big Data Analysis Reforming Education Sector through Big Data Said Rabah Azzam, Ylber Ramadani Department of Engineering and Technology Cestar College Toronto, Canada. 